\title{
Margaret McCartney: We must look at the whole impact of revalidation
}

\author{
Margaret McCartney general practitioner
}

Glasgow

The UK Medical Revalidation Collaboration (Umbrella) has reported on the impact of introducing revalidation.

"Expecting appraisers to consistently evaluate doctors' fitness to practise, based on appraisal, is unlikely to be reliable," it says, adding that, "if the main impact is simply to document professional practice it might explain the significant concerns expressed about the time and resources required, with frequent statements in interviews and survey responses that it took doctors away from their patients."

Contrast this with (Health Education England chair) Keith Pearson's 2017 review of revalidation. He wrote that most doctors find revalidation "a valuable means of assuring the public that doctors are keeping themselves up to date and safe to practise."

No doctor should fail to accept the need to keep up to date and to consider the ability to practise. But we risk offering false reassurance to ourselves and to the public when we rely on such a fallible system.

The problem with appraisal is that it is two edged. It's the only route to revalidation and a licence to practise. Doctors should know this before embarking on it.

Appraisal is not an occupational health assessment, and nor is it a venue where the systemic stresses on doctors are collected, analysed, and dealt with. Appraisers are not qualified to make a judgment on whether their appraisees' health is affecting their ability to care for their patients. This is a role for the doctors' own doctor.

What is missing from implementing revalidation is any cost effectiveness judgment and a systematic examination of the harms. Hundreds of people are now employed in the appraisal process, doctors are paying private companies hundreds of pounds to generate their patient feedback, and we're all being asked to give anonymous feedback on colleagues. This means that other things in our personal or professional lives are not being done instead.

Some doctors said that the burden of completing appraisal paperwork was a deciding factor in their retirement

I wrote about the lack of evidence for appraisal a couple of years ago. ${ }^{3}$ The emails I received in response made me aware of the harms done by bullying "feedback," as well as doctors who said that the burden of completing appraisal paperwork was a deciding factor in their retirement.

We need our older doctors-not just to do the most important work of seeing and treating patients but also to provide a ballast of experience, to know when we're about to repeat follies that have previously failed. We need a far more flexible approach to revalidation, and the General Medical Council must consider the harms of defending a system that cannot provide the assurance it wants to see.

Competing interests: See www.bmj.com/about-bmj/freelance-contributors/margaretmccartney.

Provenance and peer review: Commissioned; not externally peer reviewed.

Umbrella. Evaluating the regulatory impact of medical revalidation. Feb 2018. https://www. gmc-uk.org/-/media/documents/umbrella-report-final pdf-74454378.pdf.

Pearson K. Taking revalidation forward: Sir Keith Pearson's review of medical revalidation. Jan 2017. https://www.gmc-uk.org/-/media/documents/taking-revalidation-forward--improving-the-process-of-relicensing-for-doctors_pdf-68683704.pdf.

3 McCartney M. Margaret McCartney: The false god of appraisal. BMJ 2015;351:h4982. 10.1136/bmj.h4982 26391141

Published by the BMJ Publishing Group Limited. For permission to use (where not already granted under a licence) please go to http://group.bmj.com/group/rights-licensing/ permissions 